\title{
Implementation of the Health and Social Care Act
}

The author of this Editorial, Nigel Edwards, would like to clarify that the second paragraph should have referred to 23

commissioning support units, not "23 clinical support units," as published (BMJ 2013;346:f2090, doi:10.1136/bmj.f2090).
Cite this as: BMJ 2013;346:f2173

๑ BMJ Publishing Group Ltd 2013 